\begin{tabular}{|l|l|l|l|l|l|l|}
\hline InterteXto & Uberaba & UFTM & $\begin{array}{c}\text { v. 4 } \\
\text { n. } 1\end{array}$ & p. 34-51 & 2011 - jan. / jul. & ISSN 1981-0601 \\
\hline
\end{tabular}

\title{
CONCEPÇÕES DE LÍNGUA E LINGUAGEM EM CHOMSKY, BENVENISTE E LABOV
}

\section{CONCEPTIONS OF LANGUAGE (LANGUE AND LANGAGE) IN CHOMSKY, BENVENISTE AND LABOV}

\author{
Welisson Marques ${ }^{1}$
}

\begin{abstract}
A teoria linguistica tem antes de mais como objeto um falante-ouvinte ideal, situado numa comunidade linguística completamente homogênea, que conhece sua língua perfeitamente. CHOMSKY
\end{abstract}

A língua recorre a uma série de termos distintos que se referem não à instância do discurso, mas aos objetos reais, aos tempos e lugares históricos. [...] Uma língua sem expressão da pessoa é inconcebível. BENVENISTE

O objeto da linguística tem de ser o instrumento de comunicação usado pela comunidade de fala.

LABOV

RESUMO: Altrivamos, por meio deste artigo, apresentar uma caracterização dos conceitos de língua e linguagem em Chomsky, Benveniste e Labov. Para tal, efetuaremos uma análise descritivo-contrastiva dessas noções com a langue saussuriana. Como os estudos linguísticos são marcados pela heterogeneidade, concepções elementares como estas (de língua e linguagem), se apresentam peculiares em cada campo da Linguística, quer seja no gerativismo, na teoria da enunciação e na sociolinguística respectivamente, evidenciando, assim, a riqueza e fecundidade da área.

PALAVRAS-CHAVE: Língua; Linguagem; Chomsky; Benveniste; Labov.

ABSTRACT: Our aim, through this paper, is to present a characterization of the concepts of language (langue and langage) in Chomsky, Benveniste and also Labov. For this, we will make a descriptive and contrastive analysis of theses notions with the saussurian langue. As the Linguistic Studies are marked by heterogeneity, elementary conceptions like these (of langue and langage), show to be peculiar in each field of Linguistics, that is, in Generativism, in the Enunciation theory, and in Sociolinguistics respectively, showing, thus, the richness and fecundity of this area of study.

\footnotetext{
${ }^{1}$ Doutorando e Mestre em Estudos Linguísticos com Louvor e Distinção pelo Programa de PósGraduação em Estudos Linguísticos da Universidade Federal de Uberlândia (PPGEL-UFU). welissonmarques@yahoo.com.br
} 


\begin{tabular}{|l|l|l|l|l|l|l|}
\hline InterteXto & Uberaba & UFTM & $\begin{array}{l}\text { v. } 4 \\
\text { n. } 1\end{array}$ & p. 34-51 & 2011 - jan. / jul. & ISSN 1981-0601 \\
\hline
\end{tabular}

KEYWORDS: Language (langue); Language (langage); Chomsky; Benveniste; Labov.

\section{À guisa de um preâmbulo}

Este artigo de cunho descritivo-contrastivo propõe apresentar as noções de língua e linguagem com fulcro em três grandes teóricos da Linguística, quer sejam Noam Chomsky, Émile Benveniste e William Labov e situá-las em relação à langue saussuriana.

Os estudos da língua e linguagem, como é corrente, são marcados pela heterogeneidade. Sendo assim, concepções elementares como estas, em especial no interior desse campo do saber, se apresentam peculiares e evidenciam a riqueza e fecundidade da área. Como já bem disse Saussure, é difícil conceituar "língua" uma vez que sua definição depende exclusivamente do enfoque do pesquisador. Em outras palavras, é o ponto de vista que cria o objeto. Isso não significa que cada um possa definir o que bem entender. A este respeito, temos como "norte" o Curso de Linguística Geral (doravante CLG), obra que serve de fundamento para qualquer estudo (sério) que direta ou indiretamente lida com a língua como objeto.

A definição da langue no CLG é marcada por dualidades e paradoxos. Entre eles está o fato da linguagem ter um lado individual (fala) e outro social (língua). Outra questão é que a linguagem é ao mesmo tempo um sistema estabelecido e uma evolução. Ainda sim, a língua não é material, não se reduz aos sons, mas para ter existência precisa ser utilizada por indivíduos que os produzem, que se utilizam da articulação vocal para materializá-los ${ }^{2}$.

Nesse paradoxo que envolve o conceito de língua, abordá-la-emos a partir das reflexões dos três autores mencionados anteriormente, autores estes que, embora não sendo os únicos, são os principais nomes associados a essas três importantes teorias linguísticas: o gerativismo, a teoria da enunciação e a

\footnotetext{
${ }^{2}$ É importante salientar que além da articulação vocal, a língua pode ganhar existência empírica de outros modos, como pela escrita (manuscrita ou digitada).
} 


\begin{tabular}{|l|l|l|l|l|l|l|}
\hline InterteXto & Uberaba & UFTM & $\begin{array}{l}\text { v. 4 } \\
\text { n. } 1\end{array}$ & p. 34-51 & 2011 - jan. / jul. & ISSN 1981-0601 \\
\hline
\end{tabular}

sociolinguística. Sendo assim, antes de as analisarmos especificamente, iniciaremos este percurso partindo do conceito de langue saussuriano, ponto de referência, conforme pontuamos, para qualquer análise nesse prumo.

\section{A langue saussuriana e seu valor sistêmico}

Ferdinand de Saussure é considerado o Pai da Linguística por definir, dentro dos parâmetros formalistas da ciência, o objeto desse campo do saber, quer seja, a língua - do francês langue. Para ele, a língua é um contrato estabelecido entre os diversos membros de uma comunidade (uma vila, cidade ou mesmo nação) e todos, de um modo implícito, acatam esse contrato sendo que cada indivíduo possui em seu cérebro todo um acervo (lexical, de regras como um dicionário) de modo aproximadamente análogo aos demais membros da comunidade. Assim, torna-se possível a comunicação, isto é, todos podem se comunicar e compreender uns aos outros por meio desse acervo mais ou menos "cristalizado" e comum a todos. Se pudéssemos tomar todos esses dicionários (depositados na mente de cada indivíduo) e uni-los, abarcaríamos a língua em sua totalidade.

A língua é psíquica, incorpórea e composta por unidades mínimas significativas que unidas assumem dada forma, ou seja, a própria língua. Essas unidades denominam-se signos linguísticos, cuja formação se dá pela junção de uma imagem acústica (um significante) e um conceito (o significado). À guisa de ilustração, se tomarmos uma palavra qualquer, como casa, verificaremos que essa palavra é, grosso modo, sinônima de um signo linguístico, ou seja, ela possui uma imagem acústica /kazal ligada a um conceito "lugar de habitação ou moradia para pessoas ou mesmo animais". No entanto, é válido ressaltar que uma palavra não é equivalente a um signo. $\mathrm{O}$ signo não é a junção de uma palavra e uma coisa, mas de uma imagem acústica e uma idéia. Neste ínterim, uma palavra pode ter mais de um signo. Por exemplo, a palavra recomeço possui, no mínimo, dois signos, o prefixo re- 


\begin{tabular}{|l|l|l|l|l|l|l|}
\hline InterteXto & Uberaba & UFTM & $\begin{array}{l}\text { v. 4 } \\
\text { n. } 1\end{array}$ & p. 34-51 & 2011 - jan. / jul. & ISSN 1981-0601 \\
\hline
\end{tabular}

que é um signo, cujo significado é "repetir, relativo a algo que se repete, novamente" e outro signo, o radical começ-, que também é um significante e cujo significado é "iniciar, partir do princípio". Outro exemplo, a palavra impossibilitarão possui, ao menos, três signos. O prefixo im denotando negação, o radical possibilit indicando "possibilidade, permissão", e rão referente à terceira pessoa do plural do futuro do indicativo. De tal modo, três signos nos são apresentados nessa palavra e se porventura os separássemos, tais unidades não exprimiriam o fato linguístico em sua amplitude.

Essas considerações conduzem-nos às reflexões de Saussure em relação ao valor linguístico. O valor constitui um elemento de significação, mas ambos os conceitos (de significação e de valor) não são correspondentes. A significação está no nível do signo linguístico, da capacidade que este tem, em seu interior, de unir uma imagem acústica a uma idéia: "fazendo parte de um sistema, [uma palavra] está revestida não só de uma significação como também, e sobretudo, de um valor" (SAUSSURE, [1916] 1971, p. 134). Além dessa relação inerente ao signo linguístico, seu valor se dá em dois planos. $O$ primeiro plano em que se comprova que dada palavra pode ser trocada por outra, ou seja, que possui certa significação. E o segundo em que se pode compará-la com valores semelhantes, isto é, com palavras que se lhe podem opor. Em outros termos, uma palavra pode ser trocada por algo dessemelhante: uma idéia; como também pode ser comparada com algo da mesma natureza: outra palavra (ibid).

Assim, os termos têm os seus valores em relação ao que está fora e ao redor deles. Sobre este último, um signo tem seu valor estabelecido em relação aos demais que o antecedem e o sucedem na cadeia fônica. Sendo assim, a relação interna sígnica é limitada, pois tal significação (a ele inerente) pode ser completamente alterada pela simples presença de um termo vizinho. Sobre a relação do signo com o que lhe é externo, Saussure discorre sobre o fato de uma palavra ter o seu valor na relação com outras, quer seja, na possibilidade de compará-la às demais pertencentes ao sistema. Enfim, no plano lingüístico, 


\begin{tabular}{|l|l|l|l|l|l|l|}
\hline InterteXto & Uberaba & UFTM & $\begin{array}{l}\text { v. } 4 \\
\text { n. } 1\end{array}$ & p. 34-51 & 2011 - jan. / jul. & ISSN 1981-0601 \\
\hline
\end{tabular}

ao invés de idéias dadas ex ante, o que existe são valores que emanam do sistema (ibid).

Ademais, o signo é imaterial, como afirmamos anteriormente. Isso significa que a imagem acústica não é a palavra, muito menos o som. O som ou a palavra escrita/digitada já estão no nível da materialidade. Para Saussure, o signo está depositado na mente das pessoas e é incorpóreo, não possuindo substância alguma que o constitui. Quando o pensamento se forma, a língua, grosso modo, já está lá. O espaço de trabalho da Linguística se situa no entremeio de duas massas amorfas mentais: de um lado as idéias e de outro as imagens acústicas, ambas são inseparáveis e se imbricam na formação da língua.

Esses são, portanto, os aspectos principais da langue: ela é psíquica, imaterial, não-substancializada, pura, produz uma forma, e cujo valor se estabelece no interior do próprio sistema, nas relações que cada termo tem com os demais.

\section{A gramática gerativa chomskyana}

Noam Chomsky, linguista norte-americano, é o fundador da gramática gerativa ou generativa-transformacional. Para ele, a teoria linguistica tem como objeto "um falante-ouvinte ideal, situado numa comunidade linguistica, completamente homogênea, que conhece a sua língua perfeitamente" (1978, p. 83). O enfoque de Chomsky recai sobre o falante-ouvinte de uma sociedade, sendo que este "não [pode ser] afetado por condições gramaticalmente irrelevantes, tais como limitações de memória, distrações, desvios de atenção, erros" (ibid). Nesse sentido, é preciso realizar uma assepsia, isto é, excluir fragmentos "inapropriados" de língua, para facilitar o trabalho do linguista, com o intuito de se compreender o funcionamento de uma realidade mental, a qual se denomina estrutura profunda.

Seus estudos se voltam para essa estrutura profunda, ou seja, para a 


\begin{tabular}{|l|l|l|l|l|l|l|}
\hline InterteXto & Uberaba & UFTM & $\begin{array}{l}\text { v. 4 } \\
\text { n. } 1\end{array}$ & p. 34-51 & 2011 - jan. / jul. & ISSN 1981-0601 \\
\hline
\end{tabular}

realidade mental subjacente do falante-ouvinte. Cada indivíduo possui em seu cérebro uma gramática, que é colocada em uso e é capaz de produzir inúmeras sentenças em nível de desempenho. O linguista deve determinar, por meio dos dados do desempenho (ou performance), "o sistema subjacente de regras que foi dominado pelo falante-ouvinte e que ele põe em uso na performance efetiva" (1978, p. 84). Sendo assim, na visão chomskyana, é preciso construir teorias que expliquem esse sistema subjacente e como ele é ativado.

O conhecimento que o falante possui de sua língua denomina-se competência, ao passo que a performance (ou desempenho) é o uso efetivo da língua em situações concretas. Apesar da performance ser um reflexo da competência, as duas não são idênticas e não podem ser confundidas; isto é, uma frase no nível de estrutura profunda (competência) pode apresentar duas ou mais sentenças na estrutura de superfície (performance). Ou mesmo duas frases díspares semanticamente em nível de estrutura profunda podem emergir idênticas no nível de superfície, como é o caso das frases ambíguas. Vejamos alguns exemplos para ilustrar a questão.

A frase "meu avô faleceu" em nível de estrutura profunda pode apresentar diversas sentenças em nível de desempenho, tais como "o pai de meu pai faleceu", "meu avô morreu", "o pai de meu pai morreu". Já no nível de superfície, a sentença "a matança dos guerrilheiros" possui, ao menos, duas frases subjacentes na estrutura profunda. Pode tanto significar "os guerrilheiros mataram" ou "os guerrilheiros foram mortos". A partir dessas considerações podemos visualizar algumas contribuições advindas dos estudos gerativos. Uma delas se refere ao valor que Chomsky outorga à criatividade do falanteouvinte ideal. A intuição do falante permite trabalhar no desenvolvimento do raciocínio lógico e na capacidade de formulação de sentenças, em especial, no ensino de escrita e redação. Nesse sentido, o aluno poderia aprender a evitar a repetição, criando frases sinônimas (tecnicamente falando: criando frases análogas em nível de estrutura profunda, mas diferentes em nível de 


\begin{tabular}{|l|l|l|l|l|l|l|}
\hline InterteXto & Uberaba & UFTM & $\begin{array}{l}\text { v. } 4 \\
\text { n. } 1\end{array}$ & p. 34-51 & 2011 - jan. / jul. & ISSN 1981-0601 \\
\hline
\end{tabular}

superfície). Poderia, também, evitar a ambigüidade, usando sua intuição para perceber duas frases subjacentes àquela na estrutura de superfície, propondo uma reformulação sintática.

Chomsky tem grande interesse pela criatividade e capacidade humanas em manipular sentenças. Entretanto, alguém poderia, nesse ponto, indagar: onde está a língua nesses estudos (objeto desse artigo)? Há alguma analogia da competência com a langue saussuriana?

A este respeito, não se pode negar a grande analogia entre competência e langue. Talvez, a principal é que ambas sejam mentalistas. O estudo da competência é aquele dos procedimentos mentais, o da langue é completamente psíquico. Ambos levam em consideração, também, o caráter social da língua. Só que o enfoque chomskyano é na formação de frases, enquanto o saussuriano o é nas unidades mínimas significativas e suas relações (morfemas).

Além disso, Chomsky faz uma leitura da langue como um "inventário sistemático de itens", como algo estático que exclui o indivíduo totalmente. Essa exclusão reflete, de fato, a ótica saussuriana. Para este (Saussure), toda e qualquer mudança ou evolução diacrônica no interior do sistema depende exclusivamente do próprio sistema. Essa visão é confirmada pelo caráter arbitrário do signo em que não há relação motivada (externa) entre dada sequência de letras (significante) e um conceito (significado). Chomsky, por sua vez, valoriza o indivíduo e sua criatividade e pauta-se em Humboldt para quem a competência subjacente é "como um sistema de processos generativos" (1978, p. 84). Na teoria gerativa, os processos mentais dos indivíduos são os responsáveis por gerarem as mudanças. Dito de outro modo, o inatismo linguístico e a criatividade dos indivíduos são os responsáveis pela geração e transformação das infinitas frases da língua.

Outra diferença, mais uma crítica de Chomsky ao estruturalismo saussuriano, refere-se ao fato da ordem das palavras representar certa ordem dos pensamentos: "vale a pena indicar que esta concepção ingênua da 


\begin{tabular}{|l|l|l|l|l|l|l|}
\hline InterteXto & Uberaba & UFTM & $\begin{array}{l}\text { v. 4 } \\
\text { n. } 1\end{array}$ & p. 34-51 & 2011 - jan. / jul. & ISSN 1981-0601 \\
\hline
\end{tabular}

estrutura da linguagem persistiu até aos tempos modernos sob várias formas, verbi gratia, na imagem Saussuriana de uma sequência de expressões corresponder a uma sequência amorfa de conceitos" (1978, p. 88). Para Chomsky, a ordem natural das palavras não reflete a ordem dos pensamentos.

Voltando à noção de gramática sob os postulados gerativistas, com o intuito de melhor compreendermos a noção de língua nessa vertente, Chomsky afirma ser ela (a gramática gerativa) um sistema de regras que atribui descrições estruturais a frases. Assim, ela precisa ser capaz de atribuir, a cada uma das frases da língua, uma descrição que indique como o falante dessa língua as interpreta; além disso, tenta caracterizar "em termos tanto quanto possível neutros, o conhecimento da língua que fornece a base para o uso efetivo da mesma por um falante nativo" (1978, p. 89). Em outras palavras, a gramática pretende ser uma descrição da competência, ou seja, do conhecimento que o indivíduo possui de sua própria língua.

Sobre a organização dessa gramática, ela se subdivide em três componentes: a sintática, a semântica e a fonológica. A componente sintática determina para cada frase uma estrutura profunda - que determina sua interpretação semântica - componente semântica -, e uma estrutura de superfície - que determina sua interpretação fonética, componente fonológica (CHOMSKY, 1978, p. 98).

Outro enfoque da gramática generativa recai sobre o conhecimento intuitivo do falante sobre sua língua, que é "o padrão que determina a exatidão de qualquer gramática" (1978, p. 102). Segundo Chomsky, existem poucos estudos confiáveis que lidam com essa questão. Daí, o problema que se apresenta para o gramático é buscar construir uma descrição da intuição linguística do falante nativo.

Em consentâneo com esse viés gerativista, uma teoria da linguagem precisa satisfazer duas condições, quer sejam: a da adequação descritiva e a da adequação explicativa. A gramática de uma língua particular satisfaz a condição de adequação descritiva na medida em que oferece uma descrição 


\begin{tabular}{|l|l|l|l|l|l|l|}
\hline InterteXto & Uberaba & UFTM & $\begin{array}{l}\text { v. } 4 \\
\text { n. } 1\end{array}$ & p. 34-51 & 2011 - jan. / jul. & ISSN 1981-0601 \\
\hline
\end{tabular}

completa e minuciosa das propriedades da língua, ou seja, daquilo que o falante dessa língua sabe. $\mathrm{Na}$ adequação explicativa, a teoria deve mostrar como cada língua particular pode ser derivada de um estado inicial uniforme sob as condições-limite impostas pela experiência. Destarte, ela fornece explicação para as propriedades das línguas em um nível mais profundo (CHOMSKY, 1997).

Em relação ao inatismo, Chomsky afirma:

O que presumivelmente se defende é que a criança possui uma teoria inata sobre descrições estruturais potenciais que é suficientemente rica e desenvolvida para lhe permitir determinar, a partir de uma situação real em que ocorre um sinal, quais as descrições estruturais que podem ser apropriadas a este sinal e também para lhe permitir faze-lo, em parte, com antecipação em relação a qualquer pressuposto sobre a estrutura linguística deste sinal. (CHOMSKY, 1978, p. 115)

O gerativismo é, portanto, inatista. Para Chomsky, uma criança é capaz de produzir frases jamais ouvidas anteriormente. Essas observações são, de certa forma, um grande avanço em relação ao behaviorismo da época em que a gramática gerativa foi concebida (décadas de 1960-1970), trazendo, como consequência, uma nova visão sobre a aprendizagem de línguas. De tal sorte, ao invés de um professor prescrever regras para serem decoradas e repetidas, ele deve orientar o aluno para se apoiar em sua intuição da língua, no sentido crítico de verificar e julgar se suas frases observam as regras implícitas gramaticais - e se são adequadas para comunicação - aceitabilidade.

Um olhar cuidadoso sobre a interpretação de expressões revela bem rapidamente que desde os primeiros estágios a criança sabe muito mais do aquilo que the foi fornecido pela experiência. Nos momentos de pico do crescimento da língua, uma criança está adquirindo palavras numa velocidade aproximada de uma por hora, com exposição extremamente limitada e em condições grandemente ambíguas" (CHOMSKY, 1997, p. 54) 


\begin{tabular}{|l|l|l|l|l|l|l|}
\hline InterteXto & Uberaba & UFTM & $\begin{array}{l}\text { v. 4 } \\
\text { n. } 1\end{array}$ & p. 34-51 & 2011 - jan. / jul. & ISSN 1981-0601 \\
\hline
\end{tabular}

Por outro lado, os estudos gerativistas receberam muitas críticas pelo fato de dar pouca ênfase à performance (assim como Saussure é "perseguido" por excluir a parole do verdadeiro estudo linguístico). Para Chomsky, o estudo da performance deveria partir de uma abordagem cujo intuito é verificar se uma frase é ou não aceitável. Assim, uma frase pode ser gramatical, mas não aceitável. Por exemplo, uma frase excessivamente longa pode ser completamente gramatical, mas causar problemas de interpretação. É válido ressaltar que a gramaticalidade da frase está no nível da competência e a aceitabilidade no nível do desempenho.

Por fim, para Chomsky, os processos mentais podem ser comparados aos processos computacionais. À título de ilustração, no estudo da performance, há o dispositivo de percepção, que possui uma reserva de processos analíticos, responsável por "ativar" os sintagmas no nível de desempenho. Sendo assim, apesar de considerar a língua como fenômeno de comunicação, Chomsky é fortemente influenciado pela matemática, tanto é que o termo "gerar" advém da lógica de Post. Além disso, Chomsky é interpelado pelo estruturalismo e pela formalidade científica, portanto, ainda percebe o sistema linguístico como objetivo e separado dos fatores externos que o condicionam.

\section{A abordagem da língua e linguagem em Benveniste}

Estudar a língua nos moldes de Émile Benveniste implica uma ruptura com a concepção racionalista advinda tanto do estruturalismo saussuriano, quanto do gerativismo chomskyano. Em linhas gerais, o racionalismo afirma certa independência das idéias e da faculdade de pensar em detrimento dos objetos externos que se suporia modelá-la. Esta concepção encontra lugar em teóricos como Descartes, Arnauld e Humboldt e resulta na noção de língua psíquica conforme se pode vislumbrar nos postulados de Saussure ([1916] 1971), bem como no estudo da competência de Chomsky (1978), que, aliás, é declaradamente racionalista. 


\begin{tabular}{|l|l|l|l|l|l|l|}
\hline InterteXto & Uberaba & UFTM & $\begin{array}{l}\text { v. 4 } \\
\text { n. } 1\end{array}$ & p. 34-51 & 2011 - jan. / jul. & ISSN 1981-0601 \\
\hline
\end{tabular}

O rompimento de Benveniste com a langue se dá justamente pelo fato dele abarcar a exterioridade, em especial, as relações entre os falantes e o contexto comunicativo. No talhe epistemológico, Saussure coloca o indivíduo e outros resíduos envolvidos na enunciação no campo da parole. Benveniste, por sua vez, os traz para discussão. Para ele "não há sentido para o homem separado da linguagem" (1995, p. 285), sendo que existem signos vazios que só podem ser preenchidos na enunciação. Em outras palavras, a significação só ocorre no ato específico em si, ou seja, na relação do homem falando com outros dentro de uma comunidade.

Em Saussure a langue tem o seu valor tanto na relação de significância estabelecida entre o significante e o significado, quanto nas relações que o signo estabelece com os demais nas cadeias sintagmática e paradigmática. A primeira se refere à sua relação com os outros que o antecedem e o sucedem na cadeia fônica. Já a segunda, nas relações associativas que unem termos in absentia, ou seja, na evocação de um termo (fônico, sintagmático, lexical) com aquilo que de uma maneira ou de outra lhe é associado. Estendendo a noção de signo, Benveniste postula que o mesmo é "preenchido" na enunciação, ou seja, seu sentido rompe com o processo de significância estrutural e sistemático da langue e abarca, como exemplo, o indivíduo do enunciado. Nesse sentido, ele elucida: "de fato, uma característica das pessoas 'eu' e 'tu' é a sua unicidade específica: o 'eu' que enuncia, o 'tu' ao qual 'eu' se dirige são cada vez únicos". E ainda acrescenta que diante dessa realidade, há possibilidade de inversão do pronome, a qual se estabelece na alocução: "o que 'eu' define como 'tu' se pensa e pode inverter-se em 'eu', e 'eu' se torna um 'tu'" (BENVENISTE, 1995).

Ora, o "eu" só existe na língua porque um agente o toma para indicar uma pessoa (geralmente aquele que fala). Se se removesse a possibilidade de apontar o sujeito do enunciado e se permanecesse no nível sistemático, sua explicação cairia no nível de abstração, de um 'eu' virtual (apesar da langue ser concreta). Nesse sentido, é preciso compreender a correlação de subjetividade, 


\begin{tabular}{|l|l|l|l|l|l|l|}
\hline InterteXto & Uberaba & UFTM & $\begin{array}{l}\text { v. 4 } \\
\text { n. } 1\end{array}$ & p. 34-51 & 2011 - jan. / jul. & ISSN 1981-0601 \\
\hline
\end{tabular}

isto é, que o "eu" representa a pessoa subjetiva enquanto o "tu" a pessoa nãosubjetiva.

Essas discussões instauradas por Benveniste acerca dos pronomes nos interessam na medida em que nos permitem visualizar suas concepções de língua e linguagem. Em um nível, diríamos pragmático-contextual, fica evidente seu interesse pelas instâncias do discurso, as quais poderiam ser definidas como "atos discretos e cada vez únicos pelos quais a língua é atualizada em palavra por um locutor" (1995, p. 277). Nesse sentido, a língua é sempre reatualizada em palavra por um falante. Cada palavra tem uma significação diferente e se torna plena no ato singular da enunciação, mesmo que seja repetida, assim sendo, é possível, ao emergir no discurso, que a mesma não possua mais o mesmo referente, ou seja, o "eu" de um mesmo diálogo, pode se referir a personagens díspares.

O estudo dos pronomes demonstrativos (este, aquilo, aquela) e de advérbios como aqui, agora, ontem e amanhã é, também, exposto para reforçar a questão da designação na alocução. Estes delimitam as instâncias espacial e temporal do discurso e de modo correlato aos pronomes, só podem ser apropriadamente significados no momento da enunciação. Obviamente que esses são alguns exemplos de uma lista praticamente inesgotável de índices discursivos (anteontem, há um minuto atrás, há duas horas atrás, daqui três quartos de hora, dentro de cinco meses, só para citar alguns). Por conseguinte, para Benveniste, o essencial é "a relação entre o indicador - de pessoa, tempo, lugar, objeto mostrado, etc.- e a presente instância do discurso" (1995, p. 280).

A língua recorre a uma série de termos distintos que
correspondem um a um aos primeiros [indicadores de pessoa,
de tempo, de lugar], e que se referem não mais à instância de
discurso, mas aos objetos "reais", aos tempos e lugares
"históricos". (Ibid)

Sobre o signo vazio, explicitado anteriormente, verifica-se que seu papel é converter a linguagem em discurso, ou seja, "é identificando-se como pessoa única pronunciando eu que cada um dos locutores se propõe 


\begin{tabular}{|l|l|l|l|l|l|l|}
\hline InterteXto & Uberaba & UFTM & $\begin{array}{l}\text { v. } 4 \\
\text { n. } 1\end{array}$ & p. 34-51 & 2011 - jan. / jul. & ISSN 1981-0601 \\
\hline
\end{tabular}

alternadamente como 'sujeito'” (1995, p. 281-282). Para Benveniste, o sujeito é de extrema relevância em virtude de ser tido como ponto de referência da enunciação. Além disso, o sujeito se apropria da língua e dela faz uso.

\begin{abstract}
Muitas noções na linguística, e talvez mesmo na psicologia, aparecerão sob uma luz diferente se as restabelecermos no quadro do discurso, que é a língua enquanto assumida pelo homem que fala, e sob a condição de intersubjetividade, única que torna possível a comunicação humana. (1995, p. 293)
\end{abstract}

Outrossim, é salutar ressaltar que, sob a ótica benvenistiana, uma língua sem expressão da pessoa é inconcebível. A este respeito, ele explicita que os pronomes pessoais existem em todas as língua: "a linguagem só é possível porque cada locutor se apresenta como sujeito, remetendo a ele mesmo como eu no seu discurso" (1995, p. 286, grifo do autor).

Por fim, concluímos que Benveniste trabalha a língua no nível do discurso, discurso este que pode ser compreendido como a linguagem posta em ação. A língua é um instrumento de comunicação da linguagem e é por meio desta que o homem se constitui sujeito do discurso.

\title{
O enfoque social da língua laboviana
}

Labov, assim como Benveniste, foge da concepção de língua sistêmica e adentra no campo da exterioridade: da relação da língua(gem) com os falantes e a vida social. Para ele, é natural que os dados elementares para qualquer forma da linguística seja a língua assim como ela é usada por falantes que se comunicam no cotidiano. Todavia, ele assinala que não é esse o enfoque dado à língua pela Linguística sendo, assim, necessário considerar efetivamente seu aspecto social.

Ora, apesar de muitos linguistas partirem da noção de langue saussuriana (que é a parte social da linguagem, um contrato social estabelecido em uma determinada comunidade), os mesmos não levam em consideração, de modo algum, a vida social. Nesse sentido, tais linguistas tendem a trabalhar sempre 


\begin{tabular}{|l|l|l|l|l|l|l|}
\hline InterteXto & Uberaba & UFTM & $\begin{array}{l}\text { v. 4 } \\
\text { n. } 1\end{array}$ & p. 34-51 & 2011 - jan. / jul. & ISSN 1981-0601 \\
\hline
\end{tabular}

com um número reduzido de informantes ou, até mesmo, a examinar seu próprio conhecimento da langue em seus experimentos. Na concepção desses teóricos, alvo de suas críticas (como Martinet, por exemplo), as variações pelas quais uma língua passa se dão nas inter-relações de fatores internos, isto é, dentro do próprio sistema e não externamente, sendo que a exterioridade, para eles, não influi na evolução linguística. Um problema que gera inquietude e norteia os estudos de Labov.

Para ele, o "social" na concepção de língua saussuriana tem sido compreendido como "multi-individual", o que quer dizer que o mesmo (Saussure) não considera a relação da interação social e suas implicações sobre a língua. Como afirmamos anteriormente, definir língua não é algo simples, pois dependerá do enfoque do linguista. Isso nos remonta à dicotomia saussuriana e seu grande paradoxo: "o aspecto social da língua deve ser estudado pela observação de qualquer indivíduo, mas o aspecto individual só pode ser estudado pela observação da língua em seu contexto social" (LABOV, 2008, p. 218). Sendo assim, Labov postula a necessidade de se abordar a língua com uma base social mais abrangente. Deve-se levar em consideração que a mesma é "um instrumento de comunicação usado pela comunidade de fala" (LABOV, 2008, p. 220).

Nesse sentido, Labov também critica Chomsky. Ao seu entender, a teoria gerativa apenas reforça a dicotomia (e também separação) da langue-parole, por meio da competência-performance, sendo que os procedimentos e abordagem de estudo da língua não sofrem nenhuma ruptura. Além disso, ele critica o fato do objeto da teoria gerativa não ser a língua em si, mas sim, as intuições do indivíduo, seus julgamentos sobre quais frases são gramaticais e aceitáveis, conforme pontuamos anteriormente. Outra crítica a Chomsky recai sobre o fato de a teoria gerativa selecionar determinadas frases e excluir outras. Ou seja, o gerativismo descarta frases produzidas por falantes nativos de dada língua que são tidas como "fracas": "a gramática gerativa foi construída para produzir todas as frases aceitáveis da língua e nenhuma das 


\begin{tabular}{|l|l|l|l|l|l|l|}
\hline InterteXto & Uberaba & UFTM & $\begin{array}{l}\text { v. 4 } \\
\text { n. } 1\end{array}$ & p. 34-51 & 2011 - jan. / jul. & ISSN 1981-0601 \\
\hline
\end{tabular}

inaceitáveis" (ibid, p. 234).

Isto posto, surge uma indagação: por que o social tem sido deixado à margem dos estudos linguísticos se a língua, segundo Saussure, é social?

Em primeiro lugar, é evidente que lidar com a fala implica novos procedimentos e, mesmo, algumas dificuldades. No entanto, de acordo com Labov, embora tais dificuldades se reflitam na prática linguística até então, elas podem ser facilmente solucionáveis, pois todos os problemas (ou mitos) colocados para lidar com os dados linguísticos da comunidade de fala se revelam "ilusórios ou exagerados" (ibid, p. 237).

$\mathrm{O}$ primeiro mito se refere à agramaticalidade da fala. Acredita-se que um corpus extraído da língua falada não constitui boa evidência por ser composto por vários exemplos de frases mal formadas, elipses, inversões, as quais dificultam o trabalho analítico. Na visão de Labov, esse argumento é desmantelado quando o analista utiliza regras de editoração para gaguejos, falsos inícios, entre outros, reduzindo para menos de $2 \%$ o nível de frases realmente agramaticais e malformadas.

O segundo mito refere-se à variação na fala e na comunidade de fala. Em cada caso de variação (fonológica, sintática), "há o problema em decidir o lugar desta variação na estrutura linguística" (ibid, p. 238). Ou seja, tais variações são colocadas pelos estruturalistas e gerativistas "fora do sistema", sendo que a seleção dessas variações, como, por exemplo, o uso de falano e falando, são colocadas "abaixo" do nível da estrutura linguística.

Essas questões geram-lhe insatisfação, pois essas variações não são explicadas e quando são, se afirmam que as mesmas carecem de "status teórico nas regras da langue" (ibid). No seu entender, esse problema surge do princípio de homogeneidade da língua (cf. SAUSSURE, [1916] 1971). Para Labov, a língua não é, de modo algum, homogênea, mas sim heterogênea: "a heterogeneidade da língua é normal, comum, ela é resultado natural de fatores linguísticos fundamentais" (LABOV, 2008, p. 238). A ausência de "alternância estilística e de sistemas comunicativos multiestratificados é que seria 


\begin{tabular}{|l|l|l|l|l|l|l|}
\hline InterteXto & Uberaba & UFTM & $\begin{array}{l}\text { v. } 4 \\
\text { n. } 1\end{array}$ & p. 34-51 & 2011 - jan. / jul. & ISSN 1981-0601 \\
\hline
\end{tabular}

disfuncional" argumenta o sociolinguista (ibid). Sendo assim, se faz necessário "quebrar" a associação entre língua e homogeneidade e considerar, de uma vez por todas, as variações a ela inerentes.

O terceiro mito está ligado às dificuldades de ouvir e gravar os dados. Ad exemplus, acredita-se que os barulhos interferem na qualidade fônica dos dados e isso, conseguintemente, dificulta a análise. No entanto, com o advento de gravadores portáteis de alta qualidade, esse problema praticamente desaparece.

E o quarto e último mito é sobre as raridades das formas sintáticas, referindo-se às dificuldades em obter dados específicos, isto é, as formas específicas que são o enfoque do linguista. Para Labov, é possível desenvolver a habilidade de controlar determinadas formas de seus ouvintes, sendo que "ao final, há condições de afirmar que um falante não tem dada forma em seu sistema por causa da ausência consistente de uso dessa forma num contexto onde outros membros da comunidade a usam regularmente" (ibid).

Como se observa, apresenta-se um novo enfoque para o estudo da língua e sua definição é repensada. Na verdade, há uma ampliação teórica: a língua deve ser concebida como uma forma de comportamento social dentro de uma comunidade; é, por isso, viva e deve ser observada em seu uso corrente. Além disso, abarcar o social exige do pesquisador dados de uma parcela significativa de informantes. Segundo o sociolinguista, 25 informantes é um número suficiente.

Por fim, realizar o estudo direto da língua revela ser, na concepção laboviana, um procedimento prático e produtivo, cujas pesquisas devem usar dados primários de comunidades reais de fala, ou seja, gravações da língua em seu contexto social natural e que sejam representativas da linguagem utilizada por seus membros.

\section{Considerações Finais}




\begin{tabular}{|l|l|l|l|l|l|l|}
\hline InterteXto & Uberaba & UFTM & $\begin{array}{l}\text { v. 4 } \\
\text { n. } 1\end{array}$ & p. 34-51 & 2011 - jan. / jul. & ISSN 1981-0601 \\
\hline
\end{tabular}

Podemos resumir, em poucas palavras, que a língua, para Chomsky, insere-se em uma concepção racionalista e mentalista, cuja ênfase é na intuição do falante que pode produzir, a partir de meios finitos (do sistema linguístico), infinitas sentenças. Em virtude do inatismo e criatividade inerentes ao ser-humano, qualquer falante possui ao seu dispor uma gramática internalizada, capacitando-o a gerar e transformar orações e sentenças, diferentemente da concepção saussuriana em que as alterações lingüísticas se dão exclusivamente por mudanças no interior do próprio sistema e não externamente.

A proposta de Benveniste rompe com a langue saussuriana, com o sistema fechado. A língua, em sua concepção, abarca outras problemáticas que, para Saussure, não são contempladas pela linguística da língua. Nesse sentido, seu enfoque é na enunciação, no contexto comunicativo, nos papéis assumidos pelos falantes e na inversão de sentidos que determinado enunciado assume em relação às instâncias enunciativas. De acordo com a linguística da enunciação, as categorias de pessoa-espaço-tempo (eu-aquiagora) são constitutivas e determinantes da língua sendo que esta não pode ser pensada fora do uso que dela faz o enunciador.

Assim como Benveniste, Labov é outro linguista que percebe as insuficiências de seu objeto advindas dos postulados saussurianos. Defendese, nesse viés sociolinguista, um estudo que realmente contemple a língua em seu aspecto social, ou seja, que se paute em amostras de diálogos no contexto natural. Para ele, as dificuldades em tratar com a fala têm afastado a Linguística da comunidade falante. Assim, lidar com a língua como convenção social - e em virtude dos paradoxos que a constitui -, traz aspectos peculiares da parole para discussão, tais como o sotaque, regionalismos, processos estilísticos, variações de diversas naturezas, etc., questões que não devem ser desprezadas à luz de estudos cujo objeto se intitula "social".

Por último, como se observa, cada teórico trata as questões específicas da língua ou da linguagem de modo peculiar. Se Chomsky se volta para a 


\begin{tabular}{|l|l|l|l|l|l|l|}
\hline InterteXto & Uberaba & UFTM & $\begin{array}{l}\text { v. 4 } \\
\text { n. } 1\end{array}$ & p. 34-51 & 2011 - jan. / jul. & ISSN 1981-0601 \\
\hline
\end{tabular}

sintaxe e o estudo das intuições dos falantes, Benveniste e Labov contemplam, cada um a seu modo, diferentes aspectos da linguagem em seus postulados. Isso evidencia que nos estudos lingüísticos, ao se definir língua, é preciso, a preço de um cuidado teórico, contemplar os diversos traços que constituem o objeto do pesquisador. De tal sorte, para quem se situa fora desse campo do saber, a definição de língua poderia ser objetiva e simplista; para nós, linguistas, é um conceito complexo, pois como já bem disse Saussure, dependerá do enfoque dado pelo pesquisador; é este olhar que cria o objeto.

\section{REFERÊNCIAS}

BENVENISTE, Émile. Problemas de linguística geral. $4^{a}$ edição. Volume 1. Campinas: Editora Pontes, 1995.

CHOMSKY, Noam. Aspectos da teoria da sintaxe. $2^{a}$ ed. Coimbra: Armênio Amado, 1978.

CHOMSKY, Noam. Novos horizontes no estudo da Linguagem. DELTA. São Paulo, v. 13. n. especial. p. 49-71, 1997.

LABOV, William. Padrões sociolinguísticos. Trad. Marcos Bagno, Maria Marta Pereira Scherre, Caroline. Rodrigues Cardoso. São Paulo: Parábola, 2008.

SAUSSURE, Ferdinand. Curso de Linguística Geral. Org.por Charles Bally e Albert Sechehaye com a colaboração de Albert Riediliger. $5^{a}$ ed. São Paulo:

Cultrix, 1973. 